
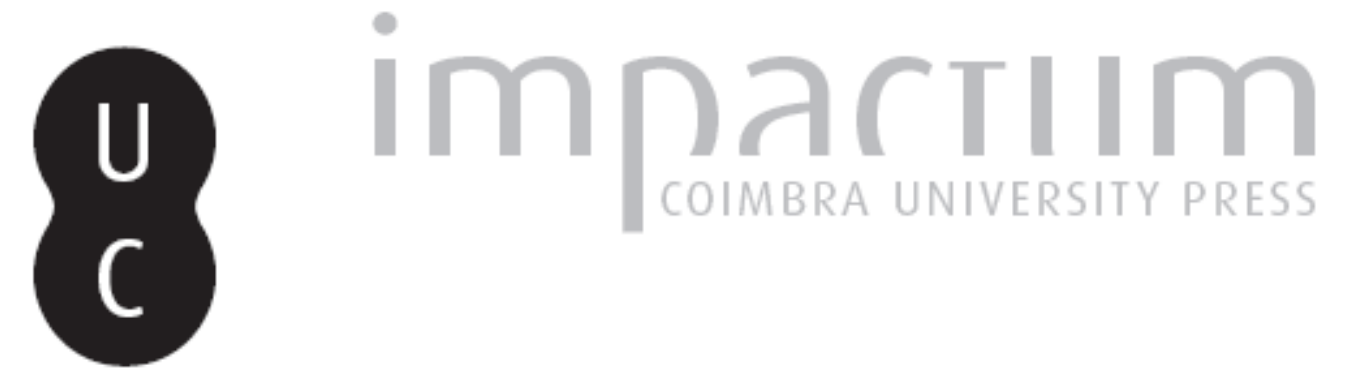

\title{
SmartCoimbra: parcerias e tendências para o desenvolvimento do turismo na região de Coimbra
}

\author{
Autor(es): $\quad$ Santos, Norberto
}

Publicado por: Imprensa da Universidade de Coimbra

URL

persistente:

URI:http://hdl.handle.net/10316.2/38320

DOI:

DOI:http://dx.doi.org/10.14195/0871-1623_34_10

Accessed : $\quad$ 26-Apr-2023 11:44:36

A navegação consulta e descarregamento dos títulos inseridos nas Bibliotecas Digitais UC Digitalis, UC Pombalina e UC Impactum, pressupõem a aceitação plena e sem reservas dos Termos e Condições de Uso destas Bibliotecas Digitais, disponíveis em https://digitalis.uc.pt/pt-pt/termos.

Conforme exposto nos referidos Termos e Condições de Uso, o descarregamento de títulos de acesso restrito requer uma licença válida de autorização devendo o utilizador aceder ao(s) documento(s) a partir de um endereço de IP da instituição detentora da supramencionada licença.

Ao utilizador é apenas permitido o descarregamento para uso pessoal, pelo que o emprego do(s) título(s) descarregado(s) para outro fim, designadamente comercial, carece de autorização do respetivo autor ou editor da obra.

Na medida em que todas as obras da UC Digitalis se encontram protegidas pelo Código do Direito de Autor e Direitos Conexos e demais legislação aplicável, toda a cópia, parcial ou total, deste documento, nos casos em que é legalmente admitida, deverá conter ou fazer-se acompanhar por este aviso.

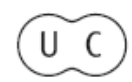




\title{
SmartCoimbra: parcerias e tendências para o desenvolvimento do Turismo na Região de Coimbra SmartCoimbra: partnerships and trends for the development of tourism in Coimbra Region
}

\author{
Norberto Santos \\ Departamento de Geografia e Turismo. Faculdade de Letras. Universidade de Coimbra e Centro de Estudos de Geografia e Ordenamento do Território \\ norgeo@ci.uc.pt
}

\section{Resumo:}

Integrada nas intervenções SmartCities, foram realizadas diversas atividades de pesquisa, discussão e avaliação, que se organizaram em diversas áreas, de forma a valorizar a qualidade de vida e a sustentabilidade territorial e dos processos. As que aqui se dá conta tomaram em consideração o Turismo, incluídas num projeto que assumiu a designação SmartCoimbra. 0 interesse do texto que se segue resulta da síntese conseguida pela participação de um número significativo de stakeholders regionais, envolvidos na atividade turística. 0 envolvimento destes parceiros permitiu a identificação de obstáculos existentes e a proposição de estratégias de atuação.

Palavras-chave: Gestão estratégica. Turismo. Coimbra. Desenvolvimento.

\section{Abstract:}

Integrated in the SmartCities interventions, several research, discussion and assessment activities were conducted, organized in a number of areas in order to value the quality of life and territorial and process sustainability. The ones mentioned here took Tourism in consideration, included in a project named SmartCoimbra. The interest of the text that follows results from the synthesis achieved by the participation of a significant number of regional stakeholders involved in tourism. The contribution of these partners allowed the identification of existing hurdles and the proposition of strategies for action.

Keywords: Strategic management. Tourism. Coimbra. Development.

\section{Esta Coimbra ${ }^{1} \ldots$}

A cidade de Coimbra "organiza-se em torno da colina que inclui o Centro Histórico, com a Alta, universitária, e a Baixa, de comércio tradicional" (SANTOS, 2013: 194), prolongando-se até ao Rossio de Santa Clara e integrando os Mosteiros da margem esquerda (Santa Clara a Velha e São Francisco - hoje em reabilitação e refuncionalização para edifício de Centro de Congressos). Sendo a cidade um elemento espacial estruturante, o seu ordenamento precisa envolver especiais cuidados no sentido da valorização da qualidade de vida das populações residentes e visitantes. Neste sentido, as preocupações ambientais e a globalização dos fenómenos deve transformar a cidade, mesmo a cidade média, como é o caso de Coimbra, num território privilegiado capaz de integrar uma complexidade significativa de relações socioeconómicas, "de funcionalidades, de estilos de vida, de culturas, de arquiteturas, de centros, de perife-

\footnotetext{
Título de um artigo constante no $\mathrm{n}^{\circ} 1$ dos Cadernos de Geografia, Revista do Instituto de Estudos Geográficos, (Esta Coimbra ... - Alguns apontamentos para uma palestra), do Professor de Geografia da Universidade de Coimbra, Alfredo Fernandes Martins (1916-1982).
}

rias, de densidades, de espaços, de paisagens, de imagens, de políticas, de intervenções, de reabilitações e revitalizações" (SANTOS, 2013: 189). Isso mesmo é referido por Martins (1983, apud SANTOS, 2001) ao afirmar Coimbra como "cidade dual por mercê de condições topográficas diversas -Alta e Baixa - (...) que cindia a aglomeração urbana [e] implicava a tradicional rivalidade entre estudantes e futricas. (...) Há no conjunto urbano uma suave sedução, que the vem do movimento topográfico, da pitoresca junção de velhos núcleos arrabaldinos à traça moderna dos bairros novos, dos muitos jardins intercalados na massa do casario, do prestígio das pedras lavradas, das flores que há por todos os recantos" (SANTOS, 2001: 267)

Complementa Martins (1983) esta representação da cidade com a identificação de Coimbra como "um centro polarizador da circulação (...), fruindo as vantagens de estar situado na zona de transição de regiões bem diversas e, por isso, de aptidão económica diferente, seja de longa data um mercado de certa importância e, paralelemente, um ponto de passagem de grande movimento. E não apenas um ponto de passagem, mas um lugar de paragem, por- 
quanto num, cruzamento de vias é banal que o fluxo do tráfego mude de sentido e substitua os meios de transporte - e daí um tempo de pausa na progressão" (MARTINS, 1983: 44).

Hoje, Esta Coimbra... continua o seu processo de evolução urbana, crescentemente planeada mas dificilmente intervencionada. A Parque Expo (2012) assume isso mesmo ao afirmar que existe uma expansão urbana periférica, relacionada com grandes superfícies comerciais e pólos universitários, acompanhada por novas áreas residenciais, que definem uma cidade policêntrica (Figura 1).

O Centro Histórico de Coimbra consegue assumir uma posição de liderança territorial, todavia, com diversas debilidades e ameaças. 0 seu fortalecimento depende da capacidade de os seus gestores: promoverem o caráter multifuncional que se vai esvaindo "reforçando a sua importância residencial, modernizando o comércio e os serviços, incentivando a instalação da 'indústria criativa', desenvolvendo o turismo e criando novas condições de atração de caráter lúdico e recreativo" (PARQUE EXPO, 2012: 97). Juntando a isto a acessibilidade bem delineada - intra-urbana, na área de influência e no País -; a conetividade e multifuncionalização qualificada da margem esquerda do Rio Mondego; a identificação do ludismo e do turismo como elementos constitutivos dos processos de ordenamento e desenvolvimento urbano (PARQUE EXPO, 2012); descobre-se o mote para ir ao encontro de uma cidade mais atrativa, mais qualificada, com mais qualidade de vida, mais eficiente e mais criativa.

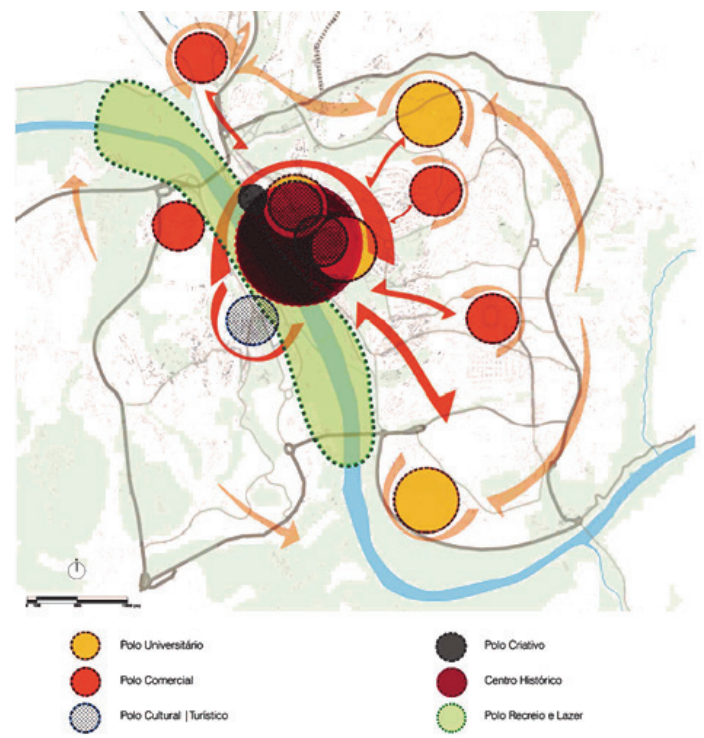

Figura 1

Modelo territorial para o Centro Histórico de Coimbra - Estrutura funcional

Fonte: PARQUE EXPO, 2012

A expansão urbana tem dado azo à valorização de novas funcionalidades e ao desenvolvimento de funcionalidades com novas roupagens e outros tempos de práticas, como sucede com os Lazeres e o Turismo, acompanhando as funções da Saúde, da Educação e da Administração Regional.

O valor social dos Lazeres é, hoje, claramente assumido, num percurso bem definido a partir do momento em que Dumazedier (1962) afirma a presença de três funções solidárias no lazer: descanso, divertimento e desenvolvimento (os três D's). Resulta esta assunção do facto de ser possível atribuir-lhes valor económico significativo (número de empregos, empreendedorismo, mais-valias associadas ao investimento e crescimento económico), com tendência manifesta de sustentabilidade ambiental, através dos elementos de identidade, autenticidade e singularidade, sendo motivo, também por isso mesmo, de uma expressão simbólica relevante no que à imagem dos territórios diz respeito. Efetivamente, "o turismo resulta, de facto, do aproveitamento dos novos valores (entre trabalho e lazer) e tempos sociais (do final de semana, passando pelo mês de férias, até ao tempo de reforma), da conjugação de fatores que contribuem para o acréscimo de mobilidade espacial, do acesso a mais informação e formação pessoal, assim como da dominância de uma perceção, amalgamada e fictícia, de livre arbítrio, identidade e imagem social, que se expressa através dos serviços e dos bens que cada um consome" (SANTOS, 2014: 451).

Não é pois de estranhar que o turismo surja como um sector de atividade económica de referência, devido à sua aceitação, por parte da população, à sua capacidade de apreciação da competitividade e ordenamento dos territórios e ao seu contributo para o desenvolvimento local e regional. Esta qualificação ganha importância quando o turismo e a cidade se tornam simbióticos permitindo "recriar incessantemente imagens e representações, expressas em relações de atuação interescalar (do local ao global). Desta forma, na cidade enuncia-se o caráter multiproduto associado à presença e justaposição de layers espaciais de influência histórica múltipla, que constituem a estrutura urbana e são aproveitados pela ação e intervenção dos diversos stakeholders como produtos turísticos. Quer isto dizer que, as cidades são marcas e destinos turísticos de primeiro nível, e assim devem ser entendidos em termos de atratividade dos diversos segmentos da procura turística" (SANTOS, 2014: 452).

Pensar no modo como a gestão destas atividades e destes territórios deve ser efectuada é fundamental para o bom sucesso das práticas de governância urbana e de gestão sistémica dos diversos elementos turísticos.

\section{Estratégias para o Turismo na Região de Coimbra}

\subsection{Metodologias utilizadas}

Qualquer discurso científico contemporâneo sublinha a importância dos processos de sustentabi- 
lidade e responsabilidade. Quando o discurso científico se inscreve simultaneamente nas lógicas operativas de gestão, planeamento e ordenamento ganham significado as estratégias que estão na base do desenvolvimento e passam pela capacidade competitiva dos territórios e empresas.

Existe uma rede de cidades, a Rede SmartCities Portugal que tem como objetivo promover o desenvolvimento e a produção de soluções urbanas inovadoras. A participação é vista numa perspetiva integrada e envolvendo, por isso, um número significativo de stakeholders a atuar direta ou indiretamente nos territórios em questão.

A referência SmartCity apenas ganha significado em português se entendida como Inteligente, Competitiva, Sustentável e encontra suporte na ideia da qualificação das cidades enquanto espaços capazes de oferecer à população que aí reside e aos que por ela passam, de forma mais intermitente, mais duradoura ou ocasional, qualidade de vida.

No caso do Turismo, aqui entendido como elemento central, os componentes criativos, os de novo turismo, as formas alternativas de valorizar os lazeres, a exploração de recursos específicos que permitam a valorização de nichos turísticos, a criatividade através de benchmarking, de cross selling, de estratégias inovadoras de recursos tradicionais, são a chave para a prossecução deste ambiente Smart (Inteligente, Competitivo, Sustentável).

Esta abordagem ganha especial fulgor quando associado ao processo de Marketing Mix, como acima foi sublinhado, especialmente a promoção, o produto e o lugar, e às estratégias de Place Branding. Como é referido no Plano Geral (2012) do SmartCoimbra "as definições que têm sido tentadas, dão particular relevo ao papel das infraestruturas de comunicação. É hoje claro que o desempenho de uma cidade em termos de qualidade urbana depende não só da capacidade das suas infraestruturas físicas (o capital físico da cidade), mas depende cada vez mais também da disponibilidade e qualidade de algo menos tangível mas absolutamente decisivo para a competitividade urbana: a educação e a infraestrutura social (o chamado capital intelectual e social e o capital de conhecimento). Foi com base neste capital intelectual, social e de conhecimento que o conceito de cidade inteligente evoluiu nos últimos tempos" (SMARTCOIMBRA, 2012: 5).

Este conceito aplica-se a cidades de tamanho médio. Estas apresentam handicaps significativos em relação às metrópoles e grandes metrópoles e concorrem com elas normalmente em desvantagem em termos de recursos e de capacidade competitiva, que alguns programas, como o SmartCity, procuram compensar. Este modelo Smart afirma a sua exequibilidade em três critérios que encontraram em Coimbra uma expressão superlativa: população urbana entre 100000 e 500000 habitantes, presença de pelo menos uma escola universitária, e é centro urbano capaz de atrair para si (área de influência regional) até 1,5 milhões de habitantes.
Como se refere na página das European SmartCities (http://www.smart-cities.eu), de forma a minimizar o efeito das mudanças económicas e tecnológicas associadas ao processo de globalização e integração em organismos supranacionais, as cidades da Europa enfrentam o desafio de combinar, em simultâneo, a competitividade e o desenvolvimento urbano sustentável. Este desafio implica impactos sobre questões como a qualidade urbana, a habitação, a economia, a cultura, as questões sociais e as condições ambientais (http://www.smart-cities.eu/ why-smart-cities.html). Valorizar de forma estratégia e através de um modelo amplamente participativo, no que aos stakeholders diz respeito, o sistema turístico associado ao destino Coimbra, é o propósito explicito.

\subsection{O SmartCoimbra Turismo}

O Plano Estratégico Nacional do Turismo (PENT) assume-se como elemento diretor das intervenções para o desenvolvimento do Turismo em Portugal, no horizonte temporal até 2015. As estratégias para o Horizonte 2020 estão em construção e organizam-se já em torno do modelo CRER (Competitividade Responsável, Estruturante e Resiliente), que materializará o próximo período de programação financeira da Política de Coesão da União Europeia. Através da valorização da qualidade, da geração da competitividade e da promoção da sustentabilidade como modelo de desenvolvimento, procura-se que a oferta do turismo nacional potencie a vocação natural de cada destino; melhore a qualidade urbana, ambiental e paisagística do território; desenvolva a participação e crie experiências distintivas e inovadoras; incremente a animação cultural, desportiva ou lúdica reforçando a imagem de marca do destino e a segmentação da clientela; qualifique e especialize continuadamente os recursos humanos envolvidos; integre conhecimento que permita qualidade do serviço, inovação e reforço da competitividade empresarial do sector. Se bem que a estratégia tenha vindo a evoluir no sentido da promoção do produto Portugal e da sua diversidade concentrada, o Turismo Centro de Portugal, em conjugação com estas estratégias, apresenta uma perspetiva própria de valorização do produto turístico. $\mathrm{Na}$ verdade, o crescimento do setor é menos significativo do que o previsto no PENT, mas salientando a importância dos produtos Touring Cultural, Turismo de Natureza, Saúde e Bem-estar e Gastronomia e Vinhos. O Turismo de Coimbra, hoje sob a alçada direta da Câmara Municipal de Coimbra, aponta, por seu lado, para a importância do City-Break, da Meeting Industry, do Turismo de Saúde, do Turismo Ativo, do Turismo Rural e do Turismo Cultural, e cada vez mais para o Turismo Religioso. Isto sucede numa cidade que é, hoje, policêntrica e multifacetada e, com uma atratividade turística assente na diversidade e na qualidade da sua História, da Monumentalidade, do Património Imaterial e dos 
Ambientes Aquáticos Fluviais, elementos de centralidade evidente ${ }^{2}$.

\section{Propostas resultantes do confronto de ideias efetuado pelo grupo de trabalho}

Foi possível verificar que existem diversos grupos de trabalho empenhados em desenvolver o turismo no âmbito territorial da região de Coimbra. Efetuou-se a identificação de um conjunto de elementos, recursos, metodologias e organizações, de relevâncias diferenciadas, no sistema turístico associado ao Destino Coimbra, que importa aqui desenvolver.

Surgem, desde logo, algumas orientações para intervenção e algumas propostas de metodologia. A perceção da importância da relação interescalar é imediatamente identificada, sendo explanados 3 níveis de atuação espacial: o local: onde se inscrevem a Meeting Industry, o Turismo cultural urbano e as Tradições de Coimbra, associadas à academia e ao fado; o sub-regional: expresso na Gastronomia e vinhos e materializado na Doçaria, no Arroz e na Lampreia, no Leitão, na Chanfana e no Espumante; o regional: valorizado no Turismo Religioso, tanto o Judaico como o Cristão Mariano; no Geoturismo e Turismo Natureza, com a valorização dos espaços naturais, geomonumentos e geossítios; e no Turismo Cultural Urbano e Cultural Rural, associado a rotas e itinerários, que explorem as diversas monumentalidades e imaterialidades, criando tempos de permanência acrescidos e níveis de atratividade elevados.

A especificação desta relação entre escalas permite algumas considerações, sendo relevante identificar e sublinhar propostas específicas.

Deixando o nível local para uma explicitação posterior neste texto, a nível sub-regional/regional, no espaço periurbano de Coimbra, integrando as vilas/cidades de proximidade (Montemor-o-Velho, Soure, Penela, Condeixa-a-Nova, Lousã, Penacova, Figueira da Foz, Cantanhede e Mealhada), a capacidade de atração permite estabelecer elos fortes que podem ser explorados turisticamente. Aqui surgem as referências de uma gastronomia rica, já acima aflorada, e que passa pela doçaria conventual ou

\footnotetext{
Os contributos para a leitura sobre os lazeres e Turismo aqui expressos são de um conjunto de stakeholders e players que são: Luís Maricato, Gestor da Caminhos d'Água, Lazer Ativo, Lda; Celeste Amaro, Diretora da Direção Regional da Cultura do Centro; Luís Meneses, Vice-reitor da Universidade de Coimbra (Turismo); Fernanda Cravidão, Diretora do Doutoramento Turismo, Lazer e Cultura, Universidade de Coimbra; Olga Cavaleiro, Presidente da Federação Portuguesa das Confrarias Gastronómicas; Claudete Moreira, Doutoranda de Turismo, Lazer e Cultura, Universidade de Coimbra; José Luís Marques, Escola de Hotelaria e Turismo de Coimbra; Joana Botelho, Consultur, Touristic Integrated Strategies e Hotel Quinta das Lágrimas; Jorge Brito, Câmara Municipal de Coimbra; Maria Adelaide Marcos, Guia-Interprete, Colaboradora do Turismo de Coimbra; Fernando Zeferino Ferreira, Câmara Municipal de Coimbra, UrbAct-CityLogo; Carina Gomes, Vereadora do Turismo da Câmara Municipal de Coimbra, António Martins, Comissão de Coordenação e Desenvolvimento Regional do Centro; Pedro Machado, Presidente da Turismo Centro de Portugal; Norberto Santos, Diretor do Mestrado Lazer, Património e Desenvolvimento, Universidade de Coimbra e moderador.
}

tradicional, estribada numa proximidade ao traçado do Mondego (Tentúgal, Pereira, Coimbra, Lorvão, Penacova, Condeixa-a-Nova). O leitão e o sarrabulho (Bairrada), o pão (Mealhada), o espumante (Bairrada) e as águas (Luso e Curia), ganham expressão com a presença da marca Coimbra. Do lado da Serra da Lousã, encontram-se os produtos associados à cabra e ao porco (Chanfana e Sopa de Casamento, arroz de bucho, negalhos) e ao mel, em Miranda do Corvo, Vila Nova de Poiares e Lousã. Nos Campos do Mondego, são o Arroz, a Lampreia e o Sável que potenciam a oferta gastronómica.

Por outro lado, todo este território sub-regional é rico em elementos relacionados com a Romanização, sendo disso expressão Conimbriga, Rabaçal e Santiago da Guarda. Esta importância mereceu a atenção do Mais Centro, que através do Programa de Valorização de Recursos Endógenos (Provere - Lojas Villa Sicó), estabeleceu orientações de promoção do património arqueológico Romano, agregando os municípios de Condeixa-a-Nova, Penela, Ansião, Alvaiázere, Soure, Ansião e Tomar, onde existe um Fórum Romano, e a que podemos ainda juntar Oliveira do Hospital (Bobadela).

Também o artesanato ganha expressão superlativa simbólica, já que o turista sente a necessidade de materializar os elementos intangíveis associados à identidade territorial e cultural. Na envolvência de Coimbra é possível encontrar uma grande qualidade de artesãos e de artefactos. Estes estão essencialmente ligados à Olaria - preta incluída -, aos Palitos Floridos e pequenos artefactos em madeira, à Cestaria, à Tecelagem, à Latoaria, à Cantaria, à Cerâmica

Por seu lado, o geoturismo vai ao encontro dos lazeres ativos, do turismo aventura e dos desportos radicais, tão procurados enquanto elementos de experiência e emoção. Aqui ganham especial relevo os territórios banhados pelo Rio Mondego; as Serras, tanto a da Lousã, como a da Boa Viagem, a do Buçaco ou as de Sicó-Alvaiázere, num primeiro anel; e as do Caramulo, Estrela e Aire-Candeeiros, num segundo anel.

Todas estas referências podem funcionar como sinergias que podem guindar a Marca Coimbra e permitir o aumento significativo do tempo de estada do turista. Historicamente importa lembrar a linha defensiva do Mondego, hoje materializada na rede de Rede dos Castelos e Muralhas do Mondego (integrando os municípios de Coimbra, da Figueira da Foz, da Lousã, de Miranda do Corvo, de Montemor-o-Velho, de Penela, de Pombal e de Soure) e no rio Mondego.

Todos estes recursos, produtos e atrações podem ser a base para a criação de rotas (algumas já presentes no mercado) que impliquem a visitação do património de uma forma integrada, de que vale a pena identificar alguns exemplos: o Rio Mondego e a sua oferta paisagística, gastronómica, patrimonial e histórica; percursos organizados com base nos ecomuseus e novas museologias, como é o caso do Museu do Sal, do Museu Underground, do Museu da Pedra, do Museu do Campo; oferta do produto sol e praia em ambiente rural, através das praias fluviais 
(Cantanhede, Coimbra, Lousã, Penacova, Penela), que associam a serra e o mar e onde a gastronomia surge como elemento incontornável da oferta turística.

A nível regional, assumindo Coimbra como centro agregador de uma região mais vasta, da raia ao mar, das Terras do Demo aos afluentes do Tejo e às praias ex-libris de Peniche, Nazaré e S. Martinho do Porto, os produtos turísticos diversificam-se: do contrabando à capeia arraiana, do termalismo às aldeias históricas e às aldeias de xisto, da vitivinicultura ao enoturismo, da festa cristã aos festejos pagãos, dos ambientes aquáticos ao turismo de montanha. As praias da Figueira da Foz, espaços de lazer de eleição de muitos residentes da Região Centro, com uma história de Casinos e Belle Époque, conjuga a sua oferta com as praias acima referidas, todas elas spots de atividades de desporto aventura, como sucede com o surf, a que podemos juntar S. Pedro de Moel, Tocha, Costa Nova, Vieira de Leiria, Torreira.

No âmbito local, quando circunscrito ao espaço urbano de Coimbra, importa dar expressão e significado à Univer(sc)idade, promovendo as sinergias e complementaridades. As ações e atividades daqui resultantes podem ser muito diversificadas. Apontam-se alguns exemplos: concertos nos espaços monumentais da Alta, especificamente na capela da Universidade, na Sé Velha, na Sé Nova, no Museu Nacional Machado de Castro, no Museu da Ciência, no Páteo das Escolas, no espaço público, nestes últimos casos em época coadunada com a realização de eventos ao ar livre; realização de feiras e mercados nos amplos espaços do Largo D. Dinis, na Rua Larga, na praça da Faculdade de Letras/Biblioteca, ou no resguardo do Páteo das Escolas, do Largo Marquês de Pombal, dos espaços exteriores do Museu Nacional Machado de Castro; abertura de um espaço comercial tradicional que expusesse a oferta e permitisse a aquisição de produtos regionais, conventuais e tradicionais (doçaria conventual e tradicional, vinhos, sal, artesanato, compotas, mel, fado, baladas...) permitindo que os produtos regionais pudessem estar presentes no espaço de visitação da Universidade. Associado a este ponto de exposição e venda é imprescindível associar espaços de sociabilização (cafetaria, casa de chá, boutique de doces, ...) que permitam ao turista permanecer durante mais algum tempo na Alta da cidade e disfrutar de um tempo de repouso e descanso no seu itinerário de visita, melhorando significativamente os níveis de satisfação. A presença de uma Loja dos Sabores num espaço de saberes, Universidade de Coimbra, seria uma aposta pertinente e uma marca que poderia ser replicada na região, promovendo os produtos alimentares e gastronómicos regionais (comidas e bebidas), o artesanato e outros produtos distintivos.

Como é percetível, Coimbra reveste-se de especial significado, em toda esta abordagem. Como elementos centrais de intervenção salienta-se, na Universidade, a sinalética interna ao espaço do Pólo I, tanto dentro como fora do Páteo das Escolas, e a necessidade absoluta de organização de rotas alter- nativas na Alta/Universidade, valorizando muitos recursos existentes e não utilizados na oferta aos visitantes (museus, arte em espaço urbano, arquiteturas com assinatura, elementos artísticos nos Edifícios do Estado Novo, Repúblicas de estudantes, recriação de praxes e comemorações estudantis, valorização de edifícios com história, tascas e tabernas, restauração e realização de festivais gastronómicos, tudo ancorado num Património Mundial da Unesco, reconhecido tanto pela traça dos seus espaços como pelo valor cultural e linguístico que representa).

Mas outros elementos pertinentes podem ser elencados. Nesta situação estão as atividades realizadas em torno do Projeto UrbAct (Innovative City Branding Management) associado ao CITYLOGO Coimbra, permitindo a identificação elementos de grande relevância para a valorização da definição de estratégias em curso. Neste âmbito, o Turismo Criativo parece ser um produto incontornável para a cidade de Coimbra, podendo ser um projeto âncora para muitos dos investimentos a efetuar no Destino Turístico Coimbra. As redes de Turismo Criativo potenciam a participação do turista no destino através de experiências diversificadas com interação significativa entre turistas e população local, como atividades educacionais, workshops, exibições de talento cultural e desportivo. Esta perspetiva permite dar protagonismo turístico a territórios que tenham potencial e abertura para atividades culturais participadas e criadas especialmente para a interação entre residentes e turistas. A integração em Rede de Turismo Criativo é um passo importante para a valorização de um novo turismo que importa explorar em Coimbra

Foram apontados mais alguns eixos de intervenção. Salientam-se: 1) os Convention \& Visitors Bureau, ancorados no Centro de Congressos de Coimbra; 2) o desenvolvimento de Aplicação Mobile com informação adequada para visita turística à região de Coimbra, com a boa definição dos conteúdos a inserir na aplicação a disponibilizar aos visitantes, conjugada com a criação de novos roteiros que explorem tanto as vertentes naturais como culturais (projeto já presente no mercado com a aplicação JiTT, com referido acima); 3) a organização de uma estrutura que permita a realização de estudos do perfil do turista que visita Coimbra e o visitante de lugares, monumentos ou espaços específicos; 4) a definição de um plano de marketing (projeto desenvolvido pela Entidade Regional de Turismo do Centro), 5) a aceção de estratégias de benchmarking para cada um dos produtos que for entendido como fulcral no desenvolvimento do destino Coimbra, e 6) ganha especial significado a Lusofonia e a sua relação com a Universidade, no sentido de valorização da Memória e da Cultura portuguesas, assumindo a Língua como um Património relevante.

A discussão sobre gestão e marketing, leva-nos à interpretação de Coimbra como imagem e marca do Centro de Portugal no âmbito Turístico, assumindo a Universidade de Coimbra (UC) como Brand Âncora. Esta assunção implica a necessidade de valorizar uma 
atuação conjugada da Câmara Municipal de Coimbra (CMC) e da UC (Turismo e Cultura), da ERT do Centro e Municípios estratégicos, do AICEP Portugal Global, E.P.E. (Agência para o Investimento e Comércio Externo de Portugal), da Associação do Turismo de Portugal, da Confederação do Turismo de Portugal e da Agência Regional de Promoção Turística Centro de Portugal, para que se efetive a promoção do território municipal/regional e que isso envolva, simultaneamente, a promoção da Universidade, de Coimbra e das outras marcas de referência no território sob a alçada do Turismo Centro de Portugal.

Importa, também, salientar ser essencial dar especial atenção ao Turista estrangeiro que visita Coimbra, questão crescentemente pertinente em função da recente integração de Coimbra na Lista dos Sítios Classificados como Património Mundial da Unesco. Estas questões, constituídas como fatores pull, devem imbricar-se com estratégias que exponenciem o papel da Agência Regional de Promoção Turística (ARPT) Centro de Portugal, através da promoção externa do território de Coimbra e do Centro de Portugal.

Fundamental é, de igual modo, organizar um calendário de eventos de referência em Coimbra, com uma antecedência que permita a divulgação junto dos stakeholders responsáveis pelas vendas, tanto em Portugal, como em mercados consolidados, em desenvolvimento ou emergentes. Conjuntamente, é imprescindível a criação de um evento que possa ser marcante no calendário nacional e internacional, possivelmente associada a recriações históricas e artes performativas. Um evento pode marcar uma cidade, mas é preciso não esquecer o envolvimento da população residente, para além de todos os stakeholders envolvidos no processo de valorização turística e desenvolvimento territorial. Na criação de valor dos eventos, importa compatibilizar os megaeventos (como concertos musicais), com outros eventos já tradicionais (como Queima das Fitas ou Festas da Rainha Santa), grandes eventos desportivos e recriações históricas.

Outro elemento a tomar em consideração é o das relações de Coimbra com as plataformas aeroportuárias, explorando a importância crescente do transporte aéreo low cost no Porto. Neste sentido, é indispensável organizar transfers que possam servir para colocar rapidamente os turistas do aeroporto no destino Coimbra através de um acordo entre hoteleiros e entidades envolvidas no turismo, tentando alargar este serviço, no tempo mais curto possível, ao aeroporto de Lisboa e aos terminais de cruzeiros de Lisboa e Leixões.

0 reconhecimento da grande abrangência territorial, integrando 100 municípios, do Turismo Centro de Portugal, dá-lhe especial relevância em todo o processo de valorização do turismo, tomando em atenção a importância das intervenções a diferentes escalas, já aqui referidas. Sublinha-se, por isso, a necessidade de financiamento para investir em turismo, nos eixos, nas ações e nas intervenções. Neste tipo de abordagem seria pertinente contar com a Comunidade Intermunicipal do Baixo Mondego para valorização do território em questão, enquanto simultaneamente se deve envolver a Comissão de Coordenação e Desenvolvimento Regional do Centro e estudar os eixos de financiamento existentes, ancorados no Plano de Ação CRER 2020.

É reconhecido o modo de gestão assumida pela Entidade Regional do Turismo do Norte. Seria de todo adequado associar ao Centro, que poucos conhecem ou localizam no estrangeiro, uma referência territorial forte como é Coimbra (Região de Coimbra e Centro). De facto, Coimbra pode alavancar o resto da região sempre num ambiente de sinergia e simbiose. A melhor maneira de atingir este objetivo é vender bem Coimbra. Para isso é necessário encontrar parceiros nos mercados internacionais para promoção do destino Coimbra.

Em todo este processo, a participação da Universidade é da maior relevância, sendo fundamental agregar esforços no sentido da concretização de objetivos. De 1 de Janeiro a 24 de Dezembro de 2013 entraram na Biblioteca Joanina mais de $240 \mathrm{mil}$ pessoas. É preciso fazer chegar a estes turistas informação sobre outros produtos de grande qualidade existentes em Coimbra e na sua Região. Claro que isto implicará, com foi dito atrás, melhorar a sinalética e, claro, divulgar de forma adequada o destino Coimbra para que quem chega a Portugal possa sentir de imediato os elementos Pull que Coimbra apresenta. Importa considerar a Universidade de Coimbra como ícone e ex-libris de toda a Região Centro, de forma a mostrar a qualidade da diversidade concentrada de produtos turísticos da Coimbra e do Centro de Portugal.

A abordagem fica a ganhar ao valorizar-se o Turismo Criativo, acima referido. Esta estratégia atingiria melhores resultados com a estruturação do produto Passaporte Turístico, de que adiante se falará. Para complementar a qualidade deste produto é fundamental a criação de um Portal internet onde seja possível aceder a todos os produtos do destino, de forma organizada e com atualização constante.

Sabendo-se do valor dos patrimónios enquanto recursos turísticos, é imperioso que se venda um Portugal que não seja apenas um monte de pedras. Para isso é necessário, como se pode depreender do que tem vindo a ser referenciado, criar conteúdos e mostrar Portugal/Coimbra através da sua história, das estórias que os territórios integram. Sabendo que todos os turistas podem contribuir para o desenvolvimento do destino, é imprescindível efetuar uma segmentação de produtos no destino, visto o produto/destino Coimbra estar muito associado a um turista muito informado culturalmente e ávido de conteúdos. Isto implica responsabilidades acrescidas no que ao embelezamento e limpeza da cidade diz respeito (sendo necessário que a CMC dê maior atenção a estas questões) assim como à abertura de espaços de sociabilização em quantidade e qualidade. Nesta perspetiva, importa relevar a importância turística e cultural do Convento de Santa Clara a Velha e criar produto no Convento de Santa Clara a Nova, assim como em toda a Margem Esquerda do 
Mondego, explorando a Centro de Congressos e as potencialidades do Observatório Astronómico, património da Universidade de Coimbra. Criar uma oferta de restauração kosher, com comida hebraica e valorizar o elemento cultural e criativo como o apoio do Festival Caminhos do Cinema Português $\left(20^{\mathrm{a}}\right.$ Edição, em 2014), alargando a sua atividade aos países de expressão portuguesa. Todos estas ações seriam de grande interesse para a atratividade turística do destino Coimbra e da região.

De referir ainda, que em Coimbra, a monumentalidade associada à religião apresenta grandes potencialidades que não se expressam num atratividade específica, porque não está organizada como um produto agregado e bem estruturado. Efetivamente é possível criar um produto de nível de atratividade superior integrando as duas Catedrais, os Colégios associados à Igreja (os da Alta e os da Rua da Sofia), os Conventos e Mosteiros (Santa Clara a Velha, Santa Clara a Nova, Santa Cruz, Sant'Ana, São Francisco, Celas, São Jorge de Milreus), o Pátio da Inquisição, as Cercas de Santo Agostinho e São Bernardo, as igrejas, de onde se destaca a de Santo António dos Olivais, o Carmelo de Santa Teresa, são alguns dos exemplos capazes de funcionar como fatores pull para o turismo religioso. Também as personalidades associadas à Religião são de renome mundial: Santo António (com fortes ligações a Pádua e à religiosidade brasileira), Rainha Santa Isabel e Irmã Lúcia. Ainda no âmbito religioso, o Turismo orientado para a comunidade judaica encontra eco nos produtos constantes na Universidade, Bíblia e documentos de Aristides de Sousa Mendes, na judiaria - entre as ruas do Corpo de Deus, Montarroio e Visconde da Luz-, na sinagoga, na estrutura medieval destinada a banhos rituais femininos judaicos, que parece ser um dos mais antigos banhos rituais judaicos (mikvá) descobertos na Europa, muito raros, nos limites da judiaria velha (Rua Visconde da Luz). Perante a atual valorização do Turismo Genealógico importa que aconteça a integração de Coimbra na rede de Judiarias. A responsabilidade da Direção Regional de Cultura do Centro na gestão da Rota das Judiarias, até 2017, pode potenciar a valorização deste produto, que crescerá na região com a exploração das relações com a Raia Portuguesa, com Cabanas de Viriato e Aristides de Sousa Mendes, com a cultura judaica de Tomar, com o espólio da Biblioteca Joanina e os espaços da judiaria de Coimbra. Todos estes recursos podem e devem ser valorizados conjuntamente com a presença Mariana, em Fátima, e a rede de Judiarias na Região Centro, a que se junta, ainda, em Coimbra, um palácio da justiça da Inquisição.

Sabendo que existem diversos lugares e monumentos considerados na Lista de Sítios Classificados Património Mundial da Unesco (Mosteiro da Batalha, Convento de Cristo, Mosteiro de Alcobaça - com fortes ligações à Rainha Santa Isabel -, Universidade de Coimbra, Alta e Sofia), no território da Região Centro, seria de todo pertinente a Marca Coimbra dar-lhes especial atenção e promove-los como âncora de mercado associada ao Turismo Património Mundial na Região Centro.
Coimbra tem que se afirmar como um ponto central de uma rede alargada onde vários produtos se cruzam e satisfazem o turista, cada vez mais predisposto para experiências diversificadas com base na emoção. É incontornável estabelecer objetivos de planeamento e promoção turística de modo a atrair turistas, a aumentar o tempo de permanência, a aumentar as receitas. De caracter imprescindível é o uso das redes sociais, dos sites específicos da hotelaria e turismo, aproveitando a divulgação que permitem. As propostas de planeamento e ação devem ser integradas e resultar de um esforço conjunto das instituições, personalidades e população, que possa resultar na ultrapassagem das entropias partidárias, administrativas e políticas no território. Todos estes eixos de ação devem tomar em muito boa atenção a concorrência direta, percebendo sempre que Portugal deve ser entendido como uma marca de Umbrela e todos somos poucos para dar o devido valor aos recursos turísticos existentes no País,

É preciso abordar a questão da qualidade da oferta turística através do contributo da melhor formação e qualificação de recursos humanos para o sucesso de um destino turístico, para que este se diferencie pelos elevados padrões de acolhimento e hospitalidade, tanto nos quadros operacionais, como nos intermédios e nos superiores. Deve ser dada uma especial atenção ao serviço turístico - acolhimento, atendimento, gastronomia e vinhos. Esta abordagem vai no sentido de atribuir um papel de significado à gastronomia e vinhos naquilo que pode ser definido como Turismo Criativo com as "aulas de cozinha" (workshops gastronómicos) para turistas, promoção de experiências a alargar a outras áreas, a outros produtos turísticos - experiências sensoriais e emoções.

Por outro lado, a hotelaria em Coimbra encontra grande concorrência com os preços praticados na hotelaria em Fátima. Na verdade a hotelaria em Coimbra precisava de parcerias e apoios que, por exemplo, reduzissem as despesas associadas a questões como o pagamento de taxas muito elevadas sobre a música ambiente, sob a alçada da Sociedade Portuguesa de Autores. Reconhece-se o esforço dos gestores e empresários hoteleiros que promovem reuniões frequentes na procura de orientações conjuntas e estratégias de ação. A conjuntura atual de parceria e diálogo institucional concertado entre o Turismo do Centro, a Câmara Municipal e a Universidade podem ser o suporte para uma evolução estratégica significativa. Nesta perspetiva, como foi referido acima, oferecer ao turista novas, cativantes e identitárias experiências é indispensável.

Neste novo ciclo que se inicia com a integração na Lista de Sítios Classificados pela Unesco como Património Mundial é fundamental valorizar o reconhecimento atribuído. 0 esperado aumento de visitantes deve ser acompanhado por uma melhoria significativa da acessibilidade e da organização do estacionamento automóvel, problema fulcral na Alta da cidade e na sua envolvência.

Tendo presente que o passado histórico em Coimbra é um património de grande valor e qualida- 
de, importa oferecer aos turistas não apenas essa história do passado mas, também, a do presente e do passado recente.

Todo o processo de oferta turística deve tomar em atenção os investimentos recentes no ordenamento urbano (Programa Polis) e explorar o Rio Mondego enquanto principal elemento natural da cidade, potenciando a relação entre a cidade e o rio, nas vertentes da sociabilização, paisagem, desporto, eventos, cultura e história.

A presença do novo Quadro Comunitário de Apoio, através do CRER e da sua orientação para o CENTRO de PORTUGAL 2020, será muito importante e baseado no modelo de Competitividade Responsável, Estruturante e Resiliente (CRER). O Turismo surge aqui ancorado no território, elemento de sustentabilidade e coesão territorial, perspetivando a região como Destino, e Coimbra como Marca de Referência. Para isso o documento aponta um conjunto de medidas que têm razão de ser estarem aqui presentes. Assim, é proposto que o desenvolvimento e qualidade do turismo irem ao encontro da valorização das melhores tecnologias disponíveis, e promoverem a sua capacidade inclusiva. Definem-se apostas abrangentes em tipos de turismo como o Turismo Médico, o de Bem-Estar, o Religioso, o Turismo de Ambiente, o Turismo Cultural, o Turismo Gastronómico, o Turismo Cinegético, o Turismo Desportivo e o Turismo Científico. Defende-se a captação de novos investidores; a consolidação de Rotas Turísticas, centradas em recursos e produtos endógenos (e.g. vinhos), artes e saberes (e.g. vidro, lanifícios e cerâmica) e na produção cultural (e.g. escritores); a aposta em novos mercados emissores emergentes, na diáspora regional, na lusofonia, na rede de alunos ERASMUS; a competência em iniciativas de marketing, promoção e comercialização da Região Centro enquanto tal e como destino turístico (TICE, sinalética, presença seletiva em feiras e eventos, segmentação); desenvolvimento de um Observatório do Turismo, orientado pelas diretrizes do European Tourism Indicator System for Sustainable Destinations; qualificação do potencial humano do setor, através de ações de formação; e Reforço da capacidade instalada regional de geração do conhecimento e de IDI na área do Turismo.

\section{Estratégias de atuação}

Torna-se imprescindível, pois, identificar alguns eixos de atuação:

- Trabalhar em rede e em parceira (no âmbito nacional e internacional), conjugando complementaridades, sinergias, contiguidades e lideranças, contando com a integração de apoios públicos e privados, envolvendo as empresas e organizações de todos os ramos. Contar com o apoio da Universidade de Coimbra, da Câmara Municipal de Coimbra, do Turismo Centro de Portugal, da Direção Regional de Cultura do Centro, da Comissão de Coordenação e Desenvolvimento Regional do Centro, da Comunidade Intermunicipal do Baixo Mondego; contar com o apoio dos Hoteleiros, dos Empresários de Animação Turística;

- Valorizar o Novo Turismo. Substituir a imagem de estandardização, pacotes rígidos, abrangência amalgamada de públicos, indiferenciados e aculturais, não preocupados ambientalmente, por uma imagem personalizada, participativa, dependente da vontade expressa do consumidor, de envolvimento cultural $e$ ambiental de flexibilidade e saber-fazer tecnológico de públicos segmentados. Promover a dimensão imaterial da oferta e dar significado ao, dando expressividade à participação do turista em experiências cativantes e com emoção;

- Identificar conteúdos que possam ser a base para Recriações Históricas e Produtos Culturais, sempre com o envolvimento da população local no sentido de criar produto no âmbito do turismo criativo.

- Programar, com uma participação significativa de stakeholders, um Calendário de Atividades que possa ser oferecido ao turista, promovendo a sua divulgação nos mercados de origem dos turistas e no destino Coimbra;

- Criar um Evento com impacto nacional e outro com Evento com projeção internacional com horizontes temporais anual e bianual, respetivamente, que devem figurar como frente de cartaz no calendário de programação acima referido;

- Valorizar as novas tecnologias oferecendo Aplicações móveis acessíveis a qualquer pessoa que visite Coimbra, user friendly e com todas as informações pertinentes ao turista: restaurantes, bares e cafés; alojamento turístico; monumentos, museus e cultura; jardins e parques; atividades de animação; espetáculos, atividades desportivas, salas de reunião e suas capacidades, equipamentos desportivos e suas capacidades e para que desportos estão homologados para competições, espaços religiosos, entre outros;

- Criar e manter um Portal de internet interativo, abrangente, e atrativo, com tradução tendo em atenção os mercados consolidados, os em desenvolvimento e os emergentes ${ }^{3}$.

- Criação de um Observatório do Turismo; criar uma estrutura, associada ao Observatório, responsável pela atualização continuada do Perfil do turista que visita a região; organizar a oferta de modo a ir ao encontro da segmentação da procura (mercados de origem - dando especial atenção à diferenciação nacional/internacional -, idade e interesses).

- Melhorar a Qualidade do Produto Coimbra; investindo na qualidade e diversidade dos equipamentos, na sinalização, na limpeza, na informação turística; investindo nos serviços prestados aos visitantes (gastronomia, animação turística, turismo de experiências, ...);

\footnotetext{
3 Hoje, encontra-se já disponível o Just in Time Tourism (JiTT). Apresenta diversas funcionalidades, com acesso offline: Mapas offline; Pontos de Interesse assinalados no mapa; Teasers de monumentos de Coimbra e pontos de interesse; Planeador de percursos, que gere o que quer ver no tempo disponível; Conteúdo escrito, incluindo o texto, detalhes sobre os pontos de interesse, contactos, horários e informações de transportes públicos (https://play.google.com/store/apps/details?id=net.iclio. jitt.tcp.coimbra.pt em 24.02.2015)
} 
- Criar um Tourism Think Tank que possa planear estrategicamente, criar opções, propor modos de atuação para o turismo, em Coimbra e na Região: Apostar em produtos como o: Turismo Religioso (Mariano, Judaico, Monumentalidade); Turismo Genealógico (Visita a Familiares e Amigos, Judaico, Brasileiro); Turismo Criativo (integração na rede de Turismo Criativo); Geoturismo (Turismo Natureza e Turismo Aventura); Meeting Industry (Turismo de Negócios); Gastronomia e Vinhos; Turismo de saúde; City-break/ Turismo Cultural e Urbano.

- Definir projetos específicos e orientados para propósitos bem definidos: Ajustar o Programa Welcome by Taxi, do Turismo de Portugal, com formação em atendimento e línguas aos taxistas, o primeiro e último agente turístico com que o visitante contacta num dado território; Criar um Passaporte Turístico segmentado (para a população das cidades geminadas com Coimbra, para os familiares de estudantes que se encontram na Universidade ao abrigo do Programa Erasmus, para os familiares de estudantes em Programas de Ensino resultantes de protocolos entre Portugal e o Brasil, para a Lusofonia e Cultura portuguesas no mundo (África, Ásia e América), para o visitante turista, em geral); Efetuar Transfers de ligação aeroportos/destino e regresso; Realizar Familiarization tours em torno de produtos associados ao território.

\section{Considerações finais}

Existe a consciência da imensidade das ações e intervenções que aqui estão propostas, mas este documento pretende funcionar como conjunto de estratégias e produtos de valorização do turismo em Coimbra e na sua região.

Importa criar, para o turista, um ambiente de satisfação, hospitalidade e segurança, que possa ser conjugado com elementos de participação efetiva, experiência e emoção partilhada. Desta forma espera-se que os produtos do destino possam ser capazes de fazer com que os territórios visitados passem a fazer parte de uma experiencia de vida que vai servir de portfólio de itinerários a divulgar junto de conhecidos e amigos.

Para isso é preciso contar uma história (estória), assegurar autenticidade, inovar com produtos alternativos, ser singular e único na identidade cultural e territorial oferecida, garantir cross-selling e satisfazer o turista.

É imprescindível e fundamental organizar os produtos em função dos territórios integrados (nível local, sub-regional e regional) e sempre com a manutenção de fortes elos entre os níveis territoriais.

Em Coimbra, no Centro Histórico e na Universidade importa dar especial atenção a pequenos elementos que podem alterar significativamente a qualidade da oferta. Na Universidade, à sinalética, à organização de rotas alternativas, à recriação histórica de elementos culturais identitários, ao património da Língua e Cultura Portuguesas, às relações, à criação de espaços de sociabilização, à constituição de um centro de visitação na Universidade onde esteja o projeto de candidatura a Património Mundial. Em Coimbra é necessária investir urgentemente na sinalética, potenciar o produto Fado e Baladas e a Recriação histórica, explorar a realização de Eventos estratégicos (Cultura, Desporto, ...), aproveitar o recurso Taberna e Tasca, dar uma qualidade superior à oferta de restauração, organizar Festivais gastronómicos.

\section{Referências Bibliográficas}

CRER 2020 (Competitividade Responsável, Estruturante e Resiliente) (2013) - Mobilização, Envolvimento, Trabalho em Rede, Ambição, Solidariedade. Plano de Ação Regional 2014-2020. CCRDC. www.gepac.gov.pt/ gepac-seminarios/cultura2020/crer-2020-pdf.aspx

DUMAZEDIER, J. (1962) - Vers une société du loisir? Éditions du Seuil, Paris.

EUROPEAN SMART CITIES - Vienna University of Technology. http:www.smart-cities.eu

MARTINS, A. F. (1983) - "Esta Coimbra: alguns apontamentos para uma palestra”. Cadernos de Geografia, 1, Instituto de Estudos Geográficos, pp. 35-78

PARQUE EXPO (2012) - A estratégia de reabilitação urbana. 2. Parte I, Visão para o Centro Histórico. https:// www.cm-coimbra.pt/index.php?option=com_ docman\&task=cat_view\&gid=750\&limit=40\&limitstar $\mathrm{t}=0$ \& 0 der $=$ date\&dir $=A$ SC\&ltemid $=381 \quad(24.02 .2015)$.

PENT (2007) - Plano Estratégico Nacional do Turismo. Para o Desenvolvimento do Turismo em Portugal. Turismo de Portugal. Ministério da Economia e da Inovação. http://www.turismodeportugal.pt/Português/ turismodeportugal/publicacoes/Documents/PENT\%20 2007.pdf

RIVAS, M. (2015) - Innovative Place Brand Management, ReLearning City Branding. URBACT- CityLogo final report. http: / / urbact.eu/sites/default/files/final_report_ urbact_citylogo_2012-2015_miguel_rivas.pdf

SANTOS, N. (2013) - "Coimbra: a organização da cidade e o centro histórico”. FERNANDES, José Rio e SPOSITO, Maria Encarnação (eds.) A nova vida do velho centro nas cidades portuguesas e brasileiras, Centro de Estudos Em Geografia e Ordenamento do Território, pp.189-210.

SANTOS, N. (2014) - "Turismo e cidades: Conhecer o turista para valorizar a ofert do turismo cultural em Coimbra". CUNHA, Lúcio e Jacinto, Rui (eds.) Paisagens e dinâmicas Territoriais em Portugal e no Brasil. As Novas Geografias dos Países de Língua Portuguesa, Âncora Editora, CEI, pp. 451-477 
SANTOS. N. (2001) - A sociedade de consumo e os espaços vividos pelas famílias. A dualidade dos espaços, a "turbulência" dos percursos e a identidade social. Edições Colibri, CEG Coimbra. 565 p.
SMARTCOIMBRA (2012) - Coimbra Inteligente e Criativa, Plano geral v1.4_2012-05-15. Documento Interno. Grupo de Trabalho SmartCities. 